\title{
MEASURING AND FORECASTING FERTILITY
}

\author{
Ene-Margit TitT \\ Institute of Mathematics and Statistics, University of Tartu, Tartu, Estonia
}

\begin{abstract}
Prognosing of fertility has been one of the most important tasks in demography and population statistics. The fertility trends have changed and have a different character in different parts of the world. The very last tendency discovered by M. Myrskylä and others about ten years ago is positive dependency on the human development index. Here the validity of this hypothesis in Europe is proved using the recent data of fertility and HDI.
\end{abstract}

Keywords: fertility; total fertility rate (TFR); human development index (HDI)

\section{POPULATION PROCESSES AND WORLD POPULATION SIZE}

Fertility is one of the most exciting problems for society. On the one hand, high fertility in developing countries causes rapid increase of world population with all the attending problems. On the other hand, in all developed countries, the most worrying issue is the ageing of population - that is an immediate consequence of low fertility.

It is understandable that all demographic processes are interdependent; there also exists a connection between demographic processes and the general development and economical level of countries. But it should be mentioned that during the last decades some processes have changed and acquired a new direction.

For long time since the homo sapiens came into being, the birth and death processes were balanced (both birth rate and death rate were extremely high), and during ten thousand generations, the growth rate of world population was only about $0.07 \%$ per generation. Of course, there were groups of individuals who became extinct, and some groups whose size increased rapidly, 
but the general development was rather uniform. The big changes started about 200 years ago - the population size started to increase rapidly. All the initial attempts to forecast the population size for the future failed.

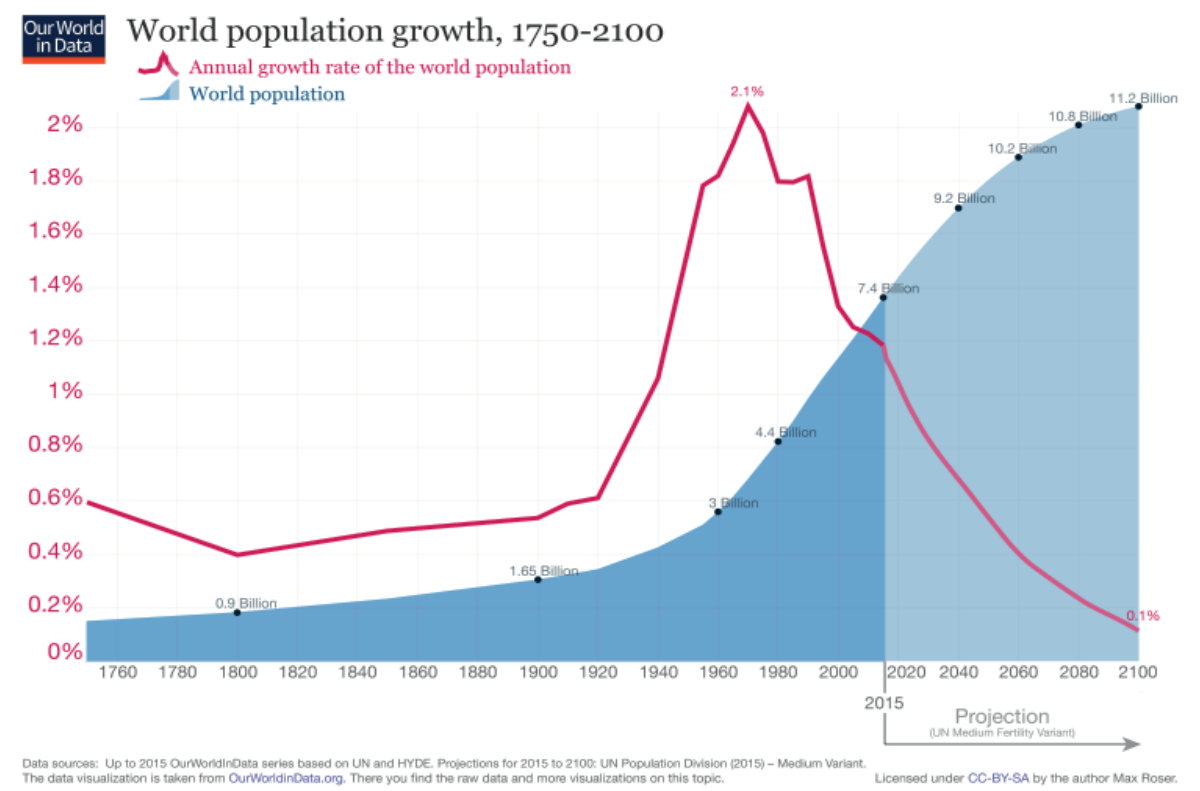

Figure 1. World population growth, 1750 - 2100. Source: Our World in Data [1]

\section{POPULATION PROCESSES. DEMOGRAPHIC TRANSITION AND ITS IMPACT}

Probably the reason was economic development, also improving sanitary conditions and medical aid. From 1800, the death rate started to decrease in more developed countries - life expectancy increased, especially in Europe. For several decades, the birth rate remained at a high level, and the population size increased, too. After one or two generations, the birth rate started to go down, and the rapid increase of population stopped. Then the similar process so-called demographic transition - started in other countries. The maximum speed of population growth was fixed in the 1960s when the population size increased more than 2 percent annually.

From this time, the birth rate has decreased in Asia and South America one reason is the falling wave of the demographic transition connected with the increasing education level of female population and accessibility of 
contraceptives. Although the fundamental connection between birth rate and death rate (or life expectancy) persists, demographic behaviour is steadily changing nowadays, and the task - to predict the population size - has become increasingly difficult.

Even the very best scientists in demography and statistics cannot say whether the world population size in 2100 will be seven or seventeen billion or some number between these extremal values.

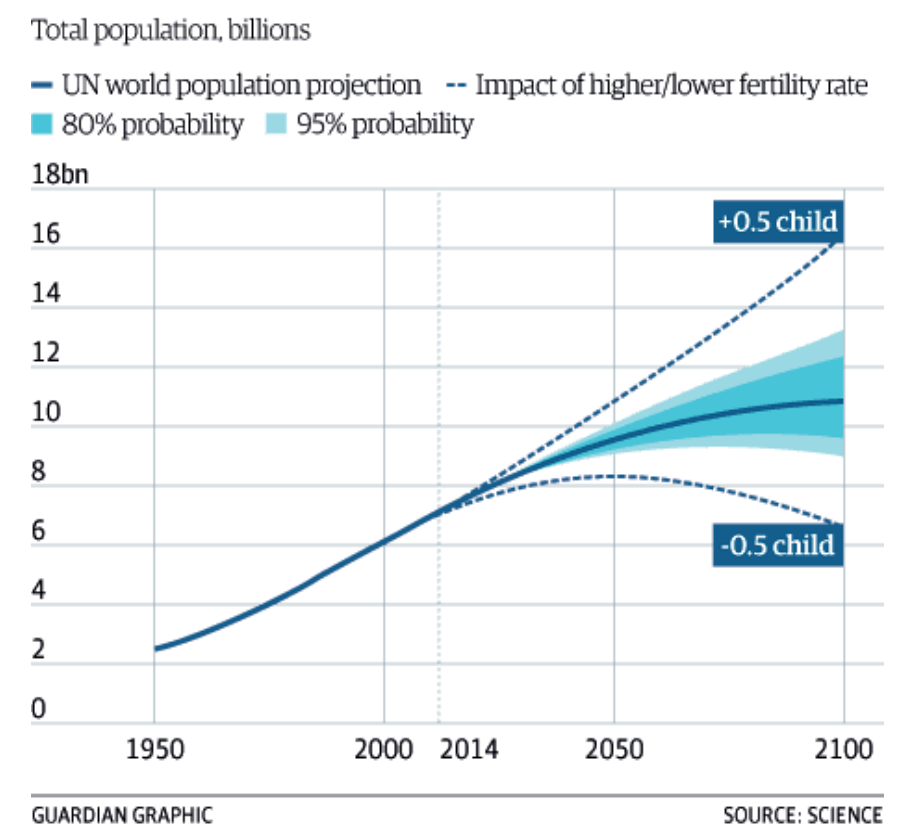

Figure 2. World population projection. Different scenarios. Source [2]

\section{MEASURING FERTILITY}

For measuring of fertility, several indicators are used. The simplest indicator is the general fertility rate that shows the number of births per 1000 women aged 15-49. Nowadays this indicator is not often used because of its impreciseness. The reason is that fertility varies greatly during the fertility period (15-49 years).

The most usual indicator of fertility is the total fertility rate (TFR), which is also used for fertility projections. But the interpretation of TFR as the "average number of children per woman" is not always exact, as it depends on changes in fertility behaviour. When the child-bearing age in a country is decreasing 
in general, then TFR overestimates the number of children per woman. When postponing of births is typical in a country, that means the average mother's age is increasing, then TFR underestimates the average number of children.

The completed fertility rate calculated for women aged 45 or 50 years shows the actual number of children delivered by age groups (cohorts) of women, but as it is calculated afterwards, it cannot be used for demographic projections.

Of course, there exist some approximate formulae for adjusting the value of TFR, but they are not very popular - so TFR is still used as main fertility indicator. The application of TFR is also explained and justified by the fact that it forecasts the increase and decrease of population size: when the mother's average age at giving birth is declining, then the population size is increasing even in the case when the completed fertility rate is less than 2. Conversely, when the postponing of births is very common, then the population size decreases even in the case when women have more than 2 children in average.

\section{FERTILITY AND INCOME}

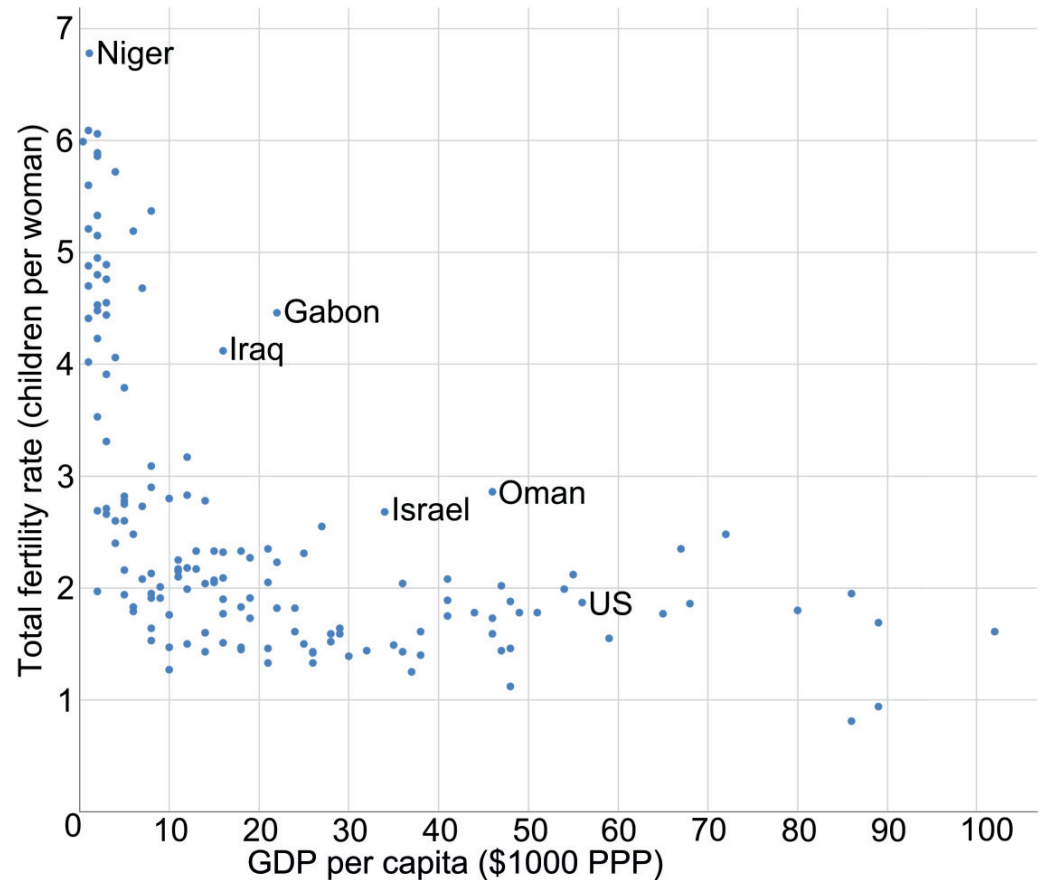

Figure 3. Fertility and income. Source: Wikipedia 
The global inverse relationship between income and fertility was already mentioned by Thomas Malthus who treated this demographic-economic paradox in his essay published in 1798 [3]. The similar trend continued at the level of both countries and individuals up to the very recent years. The newer trend (starting at the end of the 20th century) is to use the human development index instead of GDP as an explanatory variable for modelling fertility in the world [4]. The human development index has three components - GDP per capita is one of them, life expectancy is the second and the education level the third. As all these factors are negatively correlated with fertility, it can be expected that the model has quite a high description rate, see Figure 4.

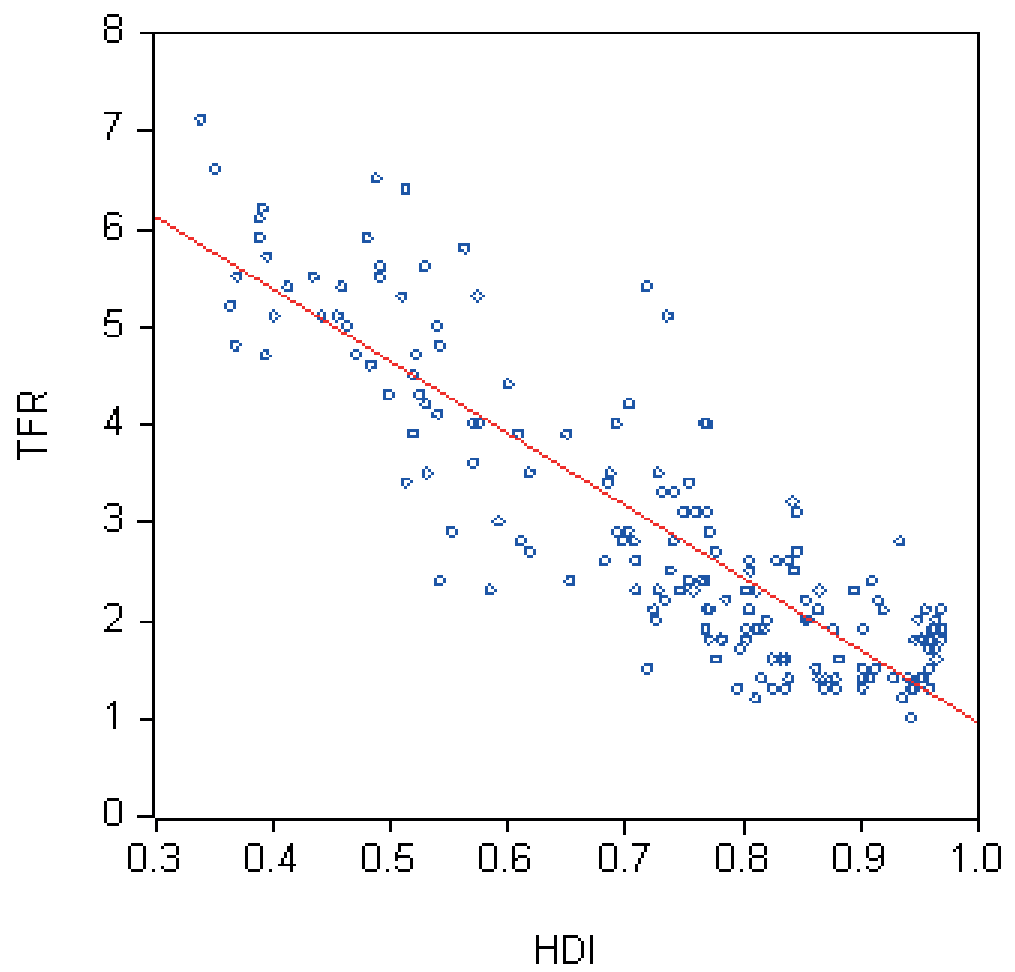

Figure 4. Connection between the human development index (HDI) and total fertility rate (TFR). Source: Wikipedia

But if we observe the right lower side of the graph, we can see a cluster of points that has a strange configuration. The Finnish demographer Myrskylä together with his colleagues examined this feature and found that some demographic processes had changed their direction in the 21 st century [5]. They formulated 
the following hypothesis: in the countries having a very high human development index ( 0,9 and more), the fertility rate measured by TFR has started to increase in the 21 st century. As a result, the connection between HDI and TFR acquires a J-shaped form, where the utmost right part of the graph turns up, see Figure 4. This result evoked a series of researches on the connections between HDI and TFR, some of which were quite critical $[6,7]$, as the positive correlation was rather low, and the future projections of increasing fertility were not reliable.

The author of the paper also checked this hypothesis using the data on TFR for the period 2010-2015 and HDI for 2015, published by the UN in 2016. It turned out that if we regard only the countries having THI higher than 0.85 , the correlation between HDI and TFR was positive. In fact, the positive correlation was quite low, but it is important that the correlation between HDI and TFR was not strongly negative, as it had been earlier, see Figure 4 .

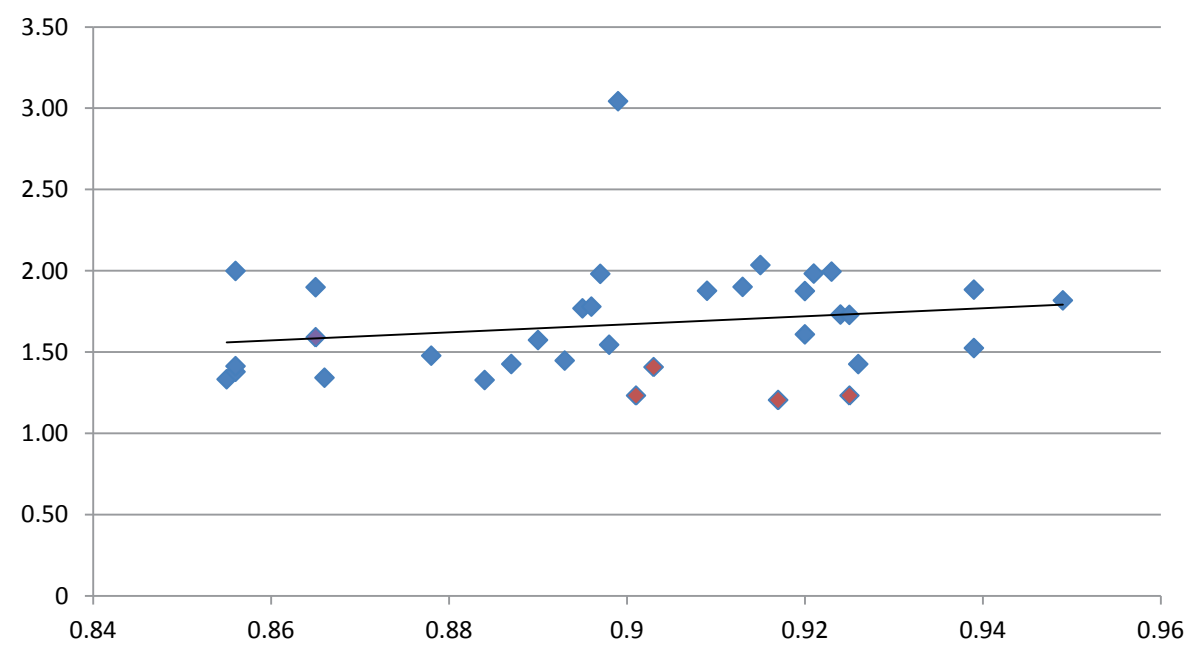

Figure 5. Plot of TFR and DHI of countries having the value of DHI more than 0.85 . The author's analysis.

It became evident that the group of countries having high HDI varies greatly by its geographical and cultural conditions. For instance, the countries of East Asia, Japan, Singapore and South Korea have very low TFRs. 


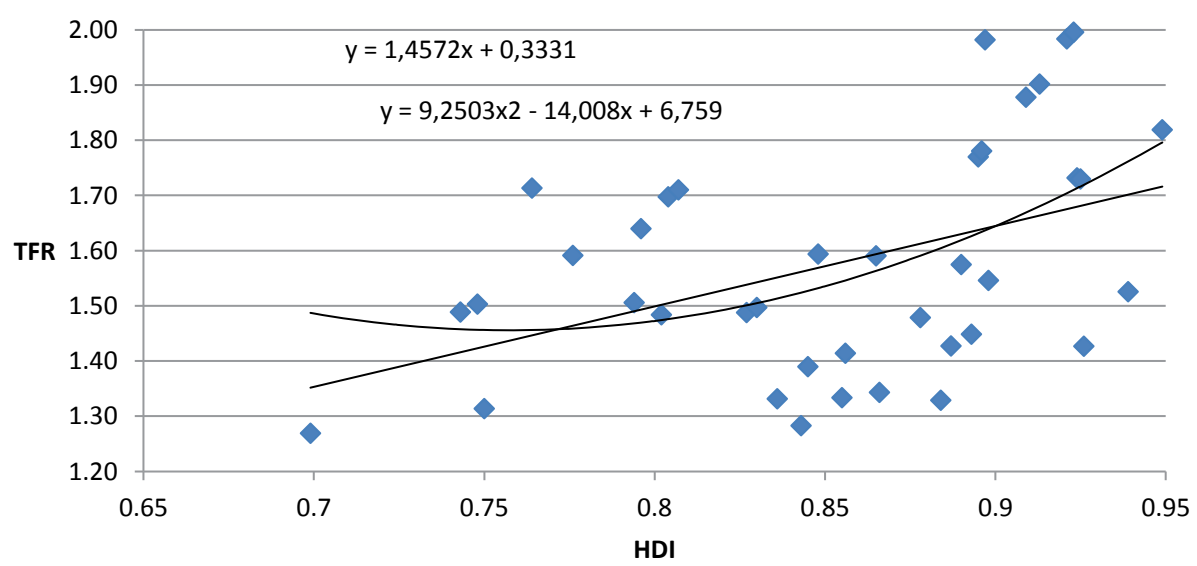

Figure 6. Plot of TFR and DHI of European countries, 2016. The author's analysis.

The next step was to calculate the correlation between TFR and HDI for European countries only. The result was positive - when 40 European countries were studied (the very small countries as Andorra, Liechtenstein, etc were excluded from the sample), then the correlation between HDI and TFR was positive (value 0.44 ), see Figure 6. From here a very important conclusion can be derived: in the European cultural space, the higher human development stimulates in general higher fertility, or the European people, living in better conditions, being more educated and having better life also wish to have more children. At the top of all these values are the Nordic countries - Sweden, Norway, Denmark, Finland and Island. It is interesting that these countries have also the top positions in a series formed by different indexes of happiness and satisfaction [8].

\section{REFERENCES}

1. https://ourworldindata.org/future-population-growth

2. https://www.theguardian.com/environment/2014/sep/18/world-populationnew-study-11bn-2100

3. Robert Malthus, An Essay on the Principle of Population, 1798, https://en.wikipedia.org/wiki/An_Essay_on_the_Principle_of_Population

4. Human Development Index. https://en.wikipedia.org/wiki/Human_Development_Index

5. Myrskylä M., Kohler H.-P., Billari F. C. (2009). Advances in development reverse fertility declines. Nature 460:7256, 741-743 
6. https://www.researchgate.net/publication/46547111_Looking_for_a_J-shaped_ development-fertility_relationship_Do_advances_in_development_really_ reverse_fertility_declines/figures?lo=1

7. Yong Cai. Hope for the World's Declining Fertility? http://www.unc.edu/ caiyong/papers/hdi.tfr.htm

8. http://worldhappiness.report 2018. https://en.wikipedia.org/wiki/World_ Happiness_Report

\section{Address for correspondence:}

Ene-Margit Tiit

Institute of Mathematics and Statistics

University of Tartu, Tartu, Estonia

J. Liivi 2-509, 50409 Tartu, Estonia

E-mail: ene.tiit@ut.ee 